\title{
Assessing Genetic Variability and Population Structure of Ziziphus Nummularia as Characterized by Phenotypic Traits and SSR Markers with Climatic Distribution
}

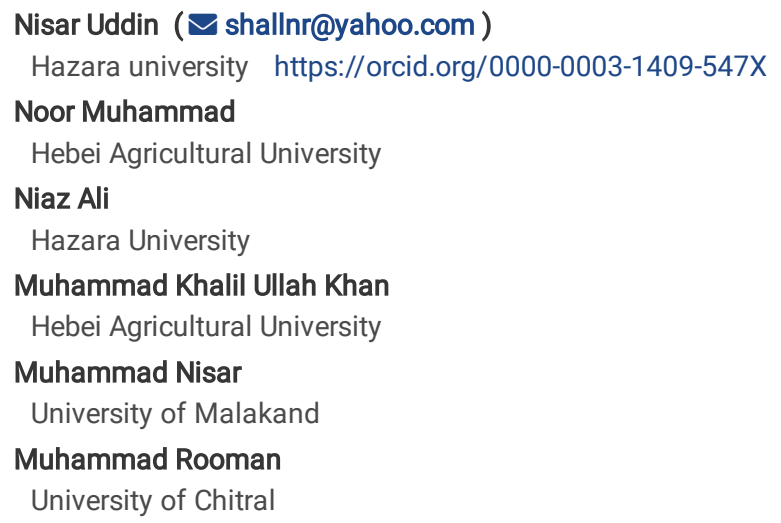

\section{Research Article}

Keywords: Z. nummularia, ArcGIS modeling, Genetic variation, Morphological traits, SSRs, Conservation

Posted Date: April 21st, 2021

DOl: https://doi.org/10.21203/rs.3.rs-432958/v1

License: (c) (i) This work is licensed under a Creative Commons Attribution 4.0 International License. Read Full License 


\section{Abstract}

Genus of Ziziphus (family Rhamnaceae), approximately 170 species of prodigious economic and ecological importance. Studies on the genetic diversity within Pakistani Ziziphus species are limited, and to date, no single report on the application of DNA barcoding attempt for identification of Ziziphus species is available in the literature. Therefore, the current study was designed to biogeographic distribution, to assess diversity based on phenotypic traits, SSRs markers, and relationships among Ziziphus nummularia (Burm.f.) Wight \& Arn. genotypes. For the first time we use ArcGIS modeling, and their cartographic function for the identification of diversity in climatic variables such as temperature, mean diurnal, humidity, precipitation, and precipitation seasonality and the using of these techniques to determine the important variable which is responsible for the recent distribution of the Ziziphus species. A total of 11 phenotypic traits were noted and have significant phenotypic variation among the traits. The study has used 40 simple sequence repeats (SSR) markers for gaining insights into the genetic diversity within 180 genotypes of $Z$. nummularia. Successful amplification was achieved with 27 SSRs and was applied for understanding the population structure and relationships among the genotypes. A total of 120 alleles were amplified from $Z$. nummularia genotypes collected from three districts of the Malakand division, alleles per locus ranged from 2 to 6 , averaging 4.4286. whereas polymorphism information content (PIC) from 0.332 to 0.794 in locus JSSR-490 and JSSR-97, within mean value was 0.671 per locus, expected heterozygosity (He), was 0.575 , observed heterozygosity (Ho), 0.6618 and average gene diversity 0.494 . Flow estimates (6.415) indicated frequent gene flow within $Z$. nummularia genotypes. Analysis of molecular variance (AMOVA) revealed high genetic variability (80\%). The genetic relationship inferred from the neighbor-joining (NJ) phylogeny separate genotypes into three clusters and Bayesian model-based STRUCTURE analyses and PCoA analysis resolved all genotypes and indicted that the KP, populations, Swat and Buner, represent excesses of two different migration routes, with one designated from Swat and Dir ( $\mathrm{L}$ ). The overall results indicated the prevalence of genetic variability and relationships among $Z$. nummularia across geographical boundaries has retained unique alleles and this may facilitate the development of agronomically desirable and genetically improved Ziziphus cultivars and collections that can help achieve efficient conservation.

\section{Introduction}

Ziziphus species family (Rhamnaceae), which has the most important and as well have been the dual function to avail tolerance to drought and drought through various physiological mechanisms including the stimulation of the oxidative metabolic pathway, regulation of osmotic pressure, and sensitive stomata closure to minimize dehydration during adverse conditions (Arndt et al. 2001), and other hand important values as used against for the control of the various hypoglycemic agent, antihypertensive agent, anti-inflammatory agent, antimicrobial agent, antioxidant agent, antitumor agent, liver protective agent, and its pharmacological properties as immune system stimulant (Hammer et al. 2001). Z. nummularia (Burm.f.) Wight \& Arn., a perennial herb commonly called small ber and wild ber which is native to southeastern Pakistan and India (Singh et al. 2015), most important and highly notably species of the Ziziphus by their known valuable values of nutritional, medically and traditionally of different parts such as fruits, leaves, root and tubers for the used various aliments i.e. ulcers, pulmonary, fevers, wounds of healing, liver troubles asthma, roots are cooling and used to treat biliousness and headache. The bark is used to treat boils and is effective against diarrhea, blood purification, antioxidants, and dysentery, etc (Hammer et al. 2001).

Different online works of literature studies rewarded for more consideration on genetic diversity such as morphological and molecular diversity as well as of their identification, e.g., resistance to different diseases, stress, and high yield production, the limited studies were recorded on the genetic diversity (Ren et al. 2015).

Information regarding genetic diversity was important for the usage of genetic resources in the breeding of wild Ziziphus species. To expand the phylogenetic genetic or genetic diversity of Ziziphus species for off coming breeding systems which are most and as well as it is necessary to realize genetic diversity and a wider population structure of released varieties and germplasm. However, in comparison with a large amount of morphological and agronomic mutations in Ziziphus (Hui-Fang et al. 2008, Liu et al. 2014), very low levels of genetic diversity were recorded by the using of different molecular marker like RFLP, RAPD, AFLP, etc. (Herselman, 2003; Nisar et al. 2019). A simple sequence repeat (SSR), a type of allele-specific molecular marker and co-dominant, has great potential to detect genetic diversity and organism relationships by their significant level of allelic polymorphisms (Ferguson et al. 2004). With their rapid development of SSR and EST-SSR genomic sequences (Gimenes et al. 2007; Tang et al. 2012). Modern or new phylogenetic cluster analysis can deliver a simple and actual way to determine the genetic assortment of genetic resource and their collections (Belamkar et al. 2011) and several other statistical system group structure, principal component analysis (PCA), and principal component coordinate analysis (PCoA), analyze the structure of the natural population via molecular markers have been developed for different plants like Apple, Sweet Sorghum, Wheat and Cucumber (Chen et al. 2012; Huang et al. 2012), rice (Liang et al. 2010).

This is the first attempt to study genotypes distribution modeling to predict the present and future habitat and various environmental variables, Furthermore, we assess the genetic diversity and structure analysis based on SSR molecular markers and morphological parameters of 180 Z. nummularia genotypes collected from various climatic regions of Pakistan. This study will be useful to optimize the management of Ziziphus and in choosing diverse parental genotypes for a future breeding program and conservation.

\section{Method And Material}

\section{Phenotypic evaluation}

Two consecutive samplings were arranged (2016- 2017) within three districts i.e. District Swat (35.2227 $\left.\mathrm{N}, 72.4258^{\circ} \mathrm{E}\right)$, Dir Lower ( $35.1977^{\circ} \mathrm{N}, 71.8749^{\circ}$ $\mathrm{E}$ ) and Buner $\left(34.3943^{\circ} \mathrm{N}, 72.6151^{\circ} \mathrm{E}\right)$ of the Malakand division Khyber Pakhtunkhwa (KP) province. A total of 180 genotypes of $Z$. nummularia were collected for the current study and 11 quantitative traits were noted viz. Plant height (PH), branching (BR), leaf length (LL), leaf width (LW), leaf types (LT), 
petiole length (PL), internode length (InL), stem diameter (StD), fruit width (FtW), fruit diameter (FtD), fruit length (FtL). In these districts, were collected 180 genotypes of Z. nummularia.

\section{Genomic DNA extraction}

Total genomic DNA was extracted from the young leaves of selected genotypes using a modified CTAB (Cetyltreimethyl ammonium bromide) method (Liu et al. 2014). Fresh leaves of Ziziphus species were ground to powder and placed into Eppendorf tube where $800 \mu \mathrm{L}$ of extraction buffer ( $3 \% \mathrm{CTAB}, 5 \mathrm{M}$ $\mathrm{NaCl}, 0.5 \mathrm{M}$ EDTA, $1 \mathrm{M}$ Tris- $\mathrm{HCl} \mathrm{pH} \mathrm{8.0)} \mathrm{with} 2 \mu \mathrm{L} \beta$-mercaptoethanol were added and incubated at $65^{\circ} \mathrm{C}$ for 30 min. Incubation was followed by adding equal volumes of chloroform: isoamyl alcohol (24:1) before centrifugation at $12,000 \mathrm{rpm}$ for $10 \mathrm{~min}$. Genomic DNA from the aqueous phase was precipitated by using ice-cold $100 \%$ ethanol at $-20^{\circ} \mathrm{C}$ for $30 \mathrm{~min}$ and centrifugation at $12,000 \mathrm{rpm}$ for 10 min. The supernatant was discarded, and the pellet washed with $70 \%$ ethanol twice and centrifuged at $12,000 \mathrm{rpm}$ for $5 \mathrm{~min}$. The concentration and quality of the extracted genomic DNA were checked using spectrophotometers (Thermo fisher scientific, USA) and by loading $5 \mu \mathrm{L}$ of DNA on $1.0 \%$ Agarose gel.

\section{PCR reaction for SSR markers}

A total of 27 pairs of SSR primers were applied to 180 genotypes of Z. nummularia (Table 1). SSRs were designed using the online program Primer 3 (http://www.frodo.wi.mit.edu/cgibin/primer3/primer3_www.cgi), annealing temperature was set from $50-60^{\circ} \mathrm{C}$, the optimal length of markers was $20 \mathrm{bp}$ and preferably with $50 \% \mathrm{GC}$ content. Polymerase chain reaction (PCR) was performed in a volume of $12.5 \mu \mathrm{L}$ containing $0.5 \mu \mathrm{L}(\sim 50 \mathrm{ng})$ genomic DNA, $6.3 \mu \mathrm{L}$ of $2 \times$ Taq Master Mix (CWBIO, Beijing), and $0.5 \mu \mathrm{L}$ of $10 \mu \mathrm{mol} / \mathrm{L}$ each of forward and reverse primers. The reaction was set for $94^{\circ} \mathrm{C}$ of denaturation for 3 min; 27 cycles of $94^{\circ} \mathrm{C}$ for $30 \mathrm{~s}, 50-60^{\circ} \mathrm{C}$ for $30 \mathrm{~s}$, and $72^{\circ} \mathrm{C}$ for $30 \mathrm{~s}$; and a final extension at $72^{\circ} \mathrm{C}$ for 10 min. PCR products were visualized using $8 \%$ denaturing polyacrylamide gel electrophoresis (PAGE) in $1 \times$ TBE buffer, and running at $200 \mathrm{~V}$ for 50 min, followed by silver staining for 10 min (Trans Gen Biotech, China).

Table 1. Description of 27 SSR pair primes used for Z. nummularia collected from different geographical regions KP, Pakistan 


\begin{tabular}{|c|c|c|c|c|c|}
\hline Locus & Repeat motif & Forward & Reverse & BP & Temp $^{\circ} \mathrm{C}$ \\
\hline JSSR-21 & $\operatorname{AT}(21)$ & ACTCATTCCGTAAATTACACAGCC & TGAATTTCTAAATTTCACCAAAAACAA & 228 & $57^{\circ} \mathrm{C}$ \\
\hline JSSR-93 & $\operatorname{TTG}(13)$ & GGAAGGACTTTGTCAGCATGGTAG & AACAGCATATTTGGATCCATTTCG & 155 & $57^{\circ} \mathrm{C}$ \\
\hline JSSR-95 & TTG(11) & CGGTGAGAGACATTTTGTTGGATT & TTCCTTACTTTCССАССTTGTTCA & 152 & $57^{\circ} \mathrm{C}$ \\
\hline JSSR-97 & TTG(9) & GTCCAAAGGCCCAACTTCTTTAGT & AGGGGACTACTCCTCTGCTGAGAT & 155 & $57^{\circ} \mathrm{C}$ \\
\hline JSSR-110 & TTA(15) & ACCTTTCGCTTAGTTCTTGCTGAA & GGACTTTTGTCCGGACCTTAAAA & 225 & $57^{\circ} \mathrm{C}$ \\
\hline JSSR-129 & TGG(9) & TGCTAATGAAAGGAACTCTGGGTC & TGATGGGTATGAAGAAGCATCAGA & 158 & $57^{\circ} \mathrm{C}$ \\
\hline JSSR-152 & TAT(18) & TCAGAATTTCTCACTTTGGCTAACAA & TGCACCGATCCTCTCCTCTC & 160 & $56^{\circ} \mathrm{C}$ \\
\hline JSSR-175 & GTT(9) & CAAAGGAAAATCTCTATGGTTGTCG & CGCTACCATGTTAAAATTTGTCCC & 155 & $57^{\circ} \mathrm{C}$ \\
\hline JSSR-181 & СТT(17) & TTTTGTCTСTСССТСТTTTCTCСА & GGCCTTTTCATGAAGCTTTTGTTA & 137 & $57^{\circ} \mathrm{C}$ \\
\hline JSSR-183 & СТT(14) & ATAGCAGCAATGGCTTTTTCTTTG & TTGAATTCCATGACATGAAGGTTG & 156 & $57^{\circ} \mathrm{C}$ \\
\hline JSSR-188 & СТT(11) & ATCTCGTTAGTGCCTATCACCAGC & ACAGGAACATAAAAGAAGAAGAACGC & 160 & $57^{\circ} \mathrm{C}$ \\
\hline JSSR-192 & CTG(9) & GCAGTTCTACATCATTCCСTCCTC & GAGATAGCATATCTGTTGGGTGGG & 157 & $56^{\circ} \mathrm{C}$ \\
\hline JSSR-207 & САТ(8) & CCAAACACCAACCTTGTAATTGGT & TGTTCATGGAGACGATAAATCTGTTACT & 160 & $55^{\circ} \mathrm{C}$ \\
\hline JSSR-209 & $\mathrm{CAG}(8)$ & AATGATCATGGGGAAACCAGTAGA & СTTCACTGCTCTGTTTGCTGTTGT & 153 & $57^{\circ} \mathrm{C}$ \\
\hline JSSR-239 & $\operatorname{ATG}(12)$ & GCAAGTACCATACACAGGATACGTC & GCATAAAGTTTGTGGAAAACGTAATTT & 158 & $58^{\circ} \mathrm{C}$ \\
\hline JSSR-222 & $\operatorname{ATT}(17)$ & GCAGCTGGATGAGAACCATAA & ACAATACAATACAAAGCCACATTAGTTC & 146 & $58^{\circ} \mathrm{C}$ \\
\hline JSSR-247 & $\operatorname{ATC}(11)$ & CGCTACAAGTGTGCGATTATGAAA & GCCCAAAAGCTACAATACCTACCC & 201 & $58^{\circ} \mathrm{C}$ \\
\hline JSSR-261 & ATA(10) & CTTGTCCAAAAGCTAACATACTTGC & AGGACAGTTCAGTAGGGTTTGTATTATT & 238 & $56^{\circ} \mathrm{C}$ \\
\hline JSSR-262 & ATA(9) & CGTGGACCAAGTCTATACCAAAATG & TGGTTTTTCTTCTCCTAATCCATGTG & 240 & $56^{\circ} \mathrm{C}$ \\
\hline JSSR-414 & $\mathrm{AC}(30)$ & TGCCACTAAAACGTATCCAATCAA & GGCATATCTGCTGAGGTGTATGTG & 232 & $56^{\circ} \mathrm{C}$ \\
\hline JSSR-416 & $\mathrm{AC}(26)$ & AGGGCCAAACAAATTACAAGGATT & TTGGATGTTGAAGCTGTTTTACCTC & 151 & $57^{\circ} \mathrm{C}$ \\
\hline JSSR-460 & $\mathrm{AG}(11)$ & GTTGTTCTTTTGGACCAATCCAGT & TGCATAGAACACCTTAGACAATGGAA & 240 & $56^{\circ} \mathrm{C}$ \\
\hline JSSR-465 & $\mathrm{CA}(25)$ & GGTTGTGCTCATATGGGGATGTAT & TCTCCAAGATCCTTTTTGTTTTGC & 220 & $57^{\circ} \mathrm{C}$ \\
\hline JSSR-485 & CT(28) & GTGCATGCATAAAAATCAAAACGA & GGGGTTTTATAGAAAGAGCGTGGT & 186 & $57^{\circ} \mathrm{C}$ \\
\hline JSSR-490 & CT(23) & TTTGCTTCTTGGCTTCGACTAAAG & AGCCTACACAAAGGACTCTTTCCA & 180 & $57^{\circ} \mathrm{C}$ \\
\hline JSSR-513 & $\mathrm{GA}(25)$ & TTCCTACCCCATCTGTACCTACTGT & TGGATGAATGATTGAAATGAAAAA & 223 & $57^{\circ} \mathrm{C}$ \\
\hline JSSR-774 & AGAAA(5) & ATTGGGTTAGTCGAAAAATGGTCA & CCAATCTACAAGTGCTATGAGGCA & 153 & $57^{\circ} \mathrm{C}$ \\
\hline
\end{tabular}

\section{Data Analysis}

The data analysis was performing by using different software and layers for the modeling and genetic diversity the world-climatic dataset was used for the data obtaining the bioclimatic layers of the selected studies regions, while the composition of the layers was annual precipitation, mean diurnal range, annual mean temperatures and pre-seasonality for this ArcGIS 10 software was used for thematic map-making and modeling. The morphological data for the selected genotypes traits were further analyzed for various statistical parameters were analyzed for mean, maximum, minimum, by using the statistics software, Excel, 2016.

The SSR binary data obtained from the PCR amplification of the Z. nummularia (180 genotypes) with 27 SSRs were assembled and analyzed using POPGENE-32 software. Parameters assessed included AF (Allele frequency), PB (polymorphic bands), P (\% Present), A (\% absent), He (expected heterozygosity under Hardy-Weinberg equilibrium), Ho (Observed heterozygosity), GN (Genotypes number), PIC (Polymorphic information content), * na = Observed number of alleles, * ne = Effective number of alleles, * I = Shannon's Information index and Fl= fixation index. Whereas polymorphism information content (PIC) was computed with the following formula of Botstein et al. (1980).

$P I C=1-\sum_{j=1}^{n} P_{i j}{ }^{2}$ 
Where Pij is the frequency of the $f^{\text {th }}$ allele for the $i^{\text {th }}$ locus and summation extends over $n$ alleles. The population structural analysis is based on 27 SSRs analyzed with Structure Modal Software version 2.3.4 (Pritchard et al. 2010). The optimal numbers of groups were determined by running a mixture and a frequency model related to the range of groups for $\mathrm{K}$ value (the putative number of populations). Each execution consisted of a recording period of 1,000 steps followed by 10,000, simulations of MCMC (Monte Carlo Markov Chain). The choice of the most probable K value was made by calculating the estimated probability of data recording $[\mathrm{LnP}(\mathrm{D})]$ and a hoc ho $\Delta \mathrm{K}$ statistic based on the rate of change in $\mathrm{LnP}$ (D) between the successive $\mathrm{K}$ values (Evanno et al.2005). The neighbor-joining assigned the 180 genotypes to the corresponding groups. Similarly, Principal coordinate analysis (PCoA) was a visualization technique commonly used in multivariate statistics. The neighbor-joining tree, a dendrogram is based on Nei's genetic distance matrix with MAGA 5 (Tamura et al. 2013). Genetic variation within and between populations was identified by group analysis of allele frequency estimates using analysis of molecular variance (AMOVA). Pairwise estimates of correlations between inter-individual alleles (FST), inter-group fixed index (FIS), and individual internal fixation index (FIT) were calculated using the AMOVA method in GenAlEx 6.1 (Peakall et al.2012).

\section{Results}

\section{Bioclimatic layers}

The current studies data were downloaded from the world-climatic database and ArCESRI information was applied to incorporate the data. The annual mean temp, annual precipitation, mean diurnal range, and pre-seasonality layers were applying on the mention areas of the Malakand division KP, Pakistan, while the GPS data were recorded at the point of collection where the collected samples were found the different regions such as healthy and mature plants. The annual mean temperature from low to high was noted by the different color layers while annual precipitation layers were presented in (Fig $1 \mathrm{~A}$ and $B$ ). The mean diurnal range and precipitation seasonality from low to high layers were noted by colors and while shows the overall temperature range and their distribution of the Z. nummularia in the selected three different regions of Malakand division, KP, Pakistan. Data maps were shown in (Fig 2A and $B$ and Fig 3A, B and C), respectively.

\section{Phenotypic diversity and correlation among the traits}

11 phenotypic traits were recorded for $180 \mathrm{Z}$. nummularia genotypes collected from various locations of Malakand division, which was found in variation in fruits, leaves, color etc. (Fig 4), the phenotypic diversity was using different statistical analysis. Descriptive statistics of the morphological parameters are summarized in (Table 2). The \%CV was calculated for phenotypic traits in genotypes was 90.55\%, for ZNDR (Dir (L) was 54.86, for ZNBU (Buner) was 11 , Significant variation was found for the branching (BR) among the genotypes of (3) regions, the highest value was observed for genotypes collected from ZNST (Swat) (69.46\%) followed by ZNDR (Dir (L) (41.84 \%) while, the lowest value was recorded for the genotypes collected from ZNBU (8.766\%). For LL in genotypes collected from (Swat) was (57.47\%), ZNDR (Dir L) (50.80\%), for ZNBU (9.97\%). Furthermore, the highest variation was observed for LW> $\mathrm{LT}>\mathrm{PL}>\mathrm{InL}>\mathrm{StD}>\mathrm{FtW}$. The number of FtL varied for genotypes collected from ZNST, ZNDR, ZNBU (56.10\%, 45.31\%, and 7.47\%), respectively. Furthermore, the Pearson correlation coefficient revealed a significant positive as well as a negative association $(p=0.05$ and 0.01$)$ among the studied traits of $Z$. nummularia (Table 3). Several traits revealed strong interrelationships within phenotype categories, particularly leaf traits with yield contributing traits and a few traits correlating with other categories, such as inherently linked growth and phenology-related traits (Tables 2 and 3 ).

Table 2. Descriptive Statistics of Z. nummularia genotypes collected from different geographical regions of KP, Pakistan

\begin{tabular}{|c|c|c|c|c|c|c|c|c|c|c|c|c|c|c|c|c|}
\hline \multicolumn{7}{|c|}{ Swat (ZNST) } & \multicolumn{5}{|c|}{ Dir (ZNDR) } & \multicolumn{5}{|c|}{ Buner (ZNBU) } \\
\hline Traits & NO & MN & $\mathrm{MX}$ & Mean & $\begin{array}{l}\text { Std. } \\
\text { Devi- }\end{array}$ & $\% \mathrm{CV}$ & MN & $M X$ & Mean & $\begin{array}{l}\text { Std. } \\
\text { Devi- }\end{array}$ & $\% \mathrm{CV}$ & MN & $M X$ & Mean & $\begin{array}{l}\text { Std. } \\
\text { Devi- }\end{array}$ & $\% \mathrm{CV}$ \\
\hline $\mathrm{PH}$ & 60 & 3.7 & 75.2 & 14.73 & 13.34 & 90.56 & 3 & 25 & 8.6 & 4.72 & 54.87 & 3.5 & 5.5 & 4.36 & 0.5 & 11.46 \\
\hline BR & 60 & 2 & 38 & 9.17 & 6.37 & 69.47 & 2 & 16 & 5.73 & 2.4 & 41.84 & 13.5 & 20 & 16.38 & 1.44 & 8.77 \\
\hline LL & 60 & 11.8 & 83 & 32.65 & 18.77 & 57.47 & 11.2 & 62.8 & 22.65 & 11.51 & 50.81 & 7.57 & 11.57 & 9.15 & 0.91 & 9.97 \\
\hline LW & 60 & 8.8 & 55.4 & 24.34 & 13.58 & 55.78 & 5.8 & 40.6 & 14.97 & 6.85 & 45.76 & 5.17 & 7.83 & 6.46 & 0.74 & 11.47 \\
\hline LT & 60 & 0.13 & 4.45 & 0.42 & 0.34 & 80.83 & 0.11 & 0.6 & 0.32 & 0.12 & 36.46 & 3.6 & 6.17 & 4.79 & 0.65 & 13.58 \\
\hline PL & 60 & 2.8 & 20.6 & 7.38 & 4.39 & 59.48 & 2.2 & 34.8 & 7.25 & 5.54 & 76.45 & 2.5 & 3.97 & 3.46 & 0.37 & 10.76 \\
\hline $\ln L$ & 60 & 2.18 & 65.4 & 17.27 & 10.45 & 60.5 & 1.42 & 25.2 & 13.84 & 5.4 & 39.05 & 1.67 & 5.33 & 3.53 & 0.73 & 20.75 \\
\hline StD & 60 & 1.1 & 21.6 & 4.12 & 3.25 & 78.95 & 1 & 14 & 3.19 & 2.07 & 64.9 & 9.87 & 13.03 & 11.27 & 0.68 & 6.06 \\
\hline FtW & 60 & 65 & 148 & 104 & 18.83 & 18.14 & 58.02 & 230.6 & 1.11 & 27.12 & 24.37 & 22 & 32 & 28.26 & 2.57 & 9.08 \\
\hline FtD & 60 & 4.8 & 334.8 & 25.26 & 41.9 & 165.87 & 4.2 & 28.8 & 9.71 & 4.32 & 44.45 & 3.67 & 15.53 & 4.73 & 2.04 & 43.18 \\
\hline FtL & 60 & 5.2 & 48.6 & 20.66 & 11.59 & 56.11 & 6.4 & 35.2 & 12.45 & 5.64 & 45.32 & 206.33 & 303.67 & 2.7 & 20.22 & 7.48 \\
\hline
\end{tabular}

Note: plant height $(P H)$, branching $(B R)$, leaf length $(L L)$, leaf width $(L W)$, leaf types $(L T)$, petiole length $(P L)$, internode length (InL), stem diameter (StD), fruit width (FtW), fruit diameter (FtD), fruit length (FtL), NO (Number of genotypes), MN (Minimum), MX (Maximum) and CV (Coefficient of variance)

Table 3. The correlation coefficient among Z. nummularia genotypes 


\begin{tabular}{|c|c|c|c|c|c|c|c|c|c|c|c|}
\hline \multicolumn{12}{|c|}{ Swat (ZNST) } \\
\hline & $\mathrm{PH}$ & $B R$ & LL & LW & LT & PL & $\ln L$ & StD & FtW & FtD & FtL \\
\hline $\mathrm{PH}$ & 1.00 & & & & & & & & & & \\
\hline BR & -0.04 & 1.00 & & & & & & & & & \\
\hline LL & $.386 * \star$ & $.395^{\star \star}$ & 1.00 & & & & & & & & \\
\hline LW & $.492^{\star *}$ & $.258^{*}$ & $.859 \star *$ & 1.00 & & & & & & & \\
\hline LT & -0.03 & 0.11 & 0.09 & 0.14 & 1.00 & & & & & & \\
\hline PL & 0.07 & -0.06 & -0.12 & -0.14 & 0.16 & 1.00 & & & & & \\
\hline InL & 0.10 & -0.11 & $-.335^{\star \star}$ & -.341 ** & -0.14 & 0.25 & 1.00 & & & & \\
\hline StD & $.681^{\star *}$ & -0.18 & 0.11 & $.268 *$ & 0.00 & 0.23 & 0.09 & 1.00 & & & \\
\hline FtW & -0.08 & -0.07 & 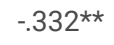 & -0.25 & 0.16 & 0.09 & 0.06 & -0.02 & 1.00 & & \\
\hline FtD & -0.04 & 0.04 & -0.02 & 0.02 & -0.03 & -0.12 & -0.21 & -0.02 & -0.16 & 1.00 & \\
\hline \multirow[t]{3}{*}{ FtL } & 0.20 & $.366^{\star \star}$ & $.341^{\star \star}$ & $.368^{\star *}$ & 0.11 & -0.18 & 0.02 & 0.16 & 0.19 & 0.14 & 1.00 \\
\hline & \multicolumn{11}{|c|}{ Dir L (ZNDR) } \\
\hline & $\mathrm{PH}$ & BR & LL & LW & LT & PL & $\operatorname{lnL}$ & StD & FtW & FtD & FtL \\
\hline $\mathrm{PH}$ & 1.00 & & & & & & & & & & \\
\hline BR & 0.14 & 1.00 & & & & & & & & & \\
\hline LL & 0.04 & $.301^{\star}$ & 1.00 & & & & & & & & \\
\hline LW & 0.15 & 0.23 & $.862^{\star *}$ & 1.00 & & & & & & & \\
\hline LT & 0.23 & 0.17 & 0.01 & 0.04 & 1.00 & & & & & & \\
\hline PL & 0.06 & 0.02 & $.565^{\star \star}$ & $.656^{\star \star}$ & -0.08 & 1.00 & & & & & \\
\hline InL & 0.11 & 0.15 & 0.02 & 0.00 & -0.01 & -0.24 & 1.00 & & & & \\
\hline StD & $.529 * \star$ & $.364^{\star \star}$ & $.313^{\star}$ & $.330 \star$ & 0.17 & 0.20 & -0.04 & 1.00 & & & \\
\hline FtW & 0.00 & 0.07 & $.278^{\star}$ & $.340 \star \star$ & 0.05 & 0.16 & 0.13 & -0.20 & 1.00 & & \\
\hline FtD & 0.09 & 0.25 & $.511^{\star \star}$ & $.559 \star \star$ & $-.324^{\star}$ & .547 ** & -0.24 & 0.20 & $.299 *$ & 1.00 & \\
\hline \multirow[t]{3}{*}{ FtL } & -0.02 & 0.07 & $.416^{\star \star *}$ & $.469 * *$ & $-.322^{*}$ & $.482^{\star *}$ & -0.19 & 0.02 & $.438^{\star \star}$ & $.785^{\star *}$ & 1.00 \\
\hline & \multicolumn{11}{|c|}{ Buner (ZNBU) } \\
\hline & $\mathrm{PH}$ & BR & LL & LW & LT & PL & $\operatorname{lnL}$ & StD & FtW & FtD & FtL \\
\hline $\mathrm{PH}$ & 1 & & & & & & & & & & \\
\hline BR & -0.012 & 1 & & & & & & & & & \\
\hline LL & -0.079 & $.475^{\star \star}$ & 1 & & & & & & & & \\
\hline LW & 0.237 & $.303^{\star}$ & $.298^{\star}$ & 1 & & & & & & & \\
\hline LT & 0.148 & $.508 * *$ & $.397 * \star$ & $.329 *$ & 1 & & & & & & \\
\hline PL & -0.037 & -0.076 & -0.065 & $-.263^{*}$ & -0.135 & 1 & & & & & \\
\hline InL & -0.205 & 0.117 & 0.19 & -0.029 & 0.032 & 0.089 & 1 & & & & \\
\hline StD & 0.149 & -0.021 & -0.016 & 0.024 & $-.260 \star$ & 0.061 & -0.174 & 1 & & & \\
\hline FtW & -0.163 & -0.018 & 0.113 & 0.072 & 0.207 & -0.093 & -0.104 & $-.300 *$ & 1 & & \\
\hline FtD & $.364^{\star \star}$ & -0.194 & -0.129 & 0.132 & 0.005 & 0.149 & $-.329 \star$ & 0.051 & 0.233 & 1 & \\
\hline FtL & $-.285^{\star}$ & 0.156 & 0.252 & -0.075 & 0.058 & 0.094 & $.352^{\star \star}$ & -0.253 & -0.143 & 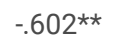 & 1 \\
\hline
\end{tabular}

**. Correlation is significant at the 0.01 level (2-tailed).*. Correlation is significant at the 0.05 level (2-tailed). 
The current research works total of 27 SSRs pair primers were successfully amplified size of the PCR bands ranged from 137 bp up to 240 bp (JSSR-181 repeat motif as CTT-17 and JSSR-460 as AG-11). Total 120 alleles were reported from 27 SSRs markers average allele was 4.42 per locus. The allele frequency at each SSRs ranged from 0.510 to 1.190 in locus number JSSR-513 and JSSR-181 respectively, the lowest number of alleles were noted at of the 11 loci range from 2 to 3 in (JSSR-21, JSSR-93, JSSR-239, JSSR-247, JSSR-261, JSSR-262, JSSR-414, JSSR-416, JSSR-485, and JSSR-490), respectively. The observed genetic diversity, PIC (polymorphic information content), ranged from 0.33 at the locus of JSSR-490 to a maximum of 0.79 at locus as JSSR-97, there were five different loci (JSSR-95, JSSR-152, JSSR-175, JSSR-188, and JSSR-513) were highly polymorphic, with PIC values higher than the other locus and where no locus was recorded with a PIC less than 0.25 , respectively.* ne = Effective number of alleles, ${ }^{*}$, Shannon's Information index and *BP Polymorphic bands were presented in (Table 4).

The observed heterozygosity (Ho) in Z. nummularia ranged from 0.070 to 0.968 in the locus JSSR-414 and JSSR-152 with an average of 0.66 and the expected heterozygosity varies from 0.140 to 0.760 in the locus JSSR-414 and JSSR-95, respectively, with an average value of 0.575 . The important information of the $Z$. nummularia genotypes, Viz, the effective number of alleles (*ne), and the Shannon information index (*I) are summarized in (Table 4). The observed number of alleles (*na) varied from 2 to 6 in the locus as JSSR-490 and JSSR-152 in Z. nummularia genotypes. The **Nei's ranged between 0.140 for locus JSSR-414 and 0.758 for locus JSSR-95. FIS varied from -0.110 to 0.816 with an average of -0.210 . The FIS values obtained for most of the populations were not significant and negative $(P>0.05)$, which suggests that there is no loss of heterozygosity. FIT, FST, and Nm* (Table 4$)$. Most of the $Z$. nummularia genotypes in population three showed abundant genetic variation and the average gene diversity is 0.4944 . The estimate of gene flow (Nm*) based on FST in all populations has an average value of 6.415 , respectively.

Table 4. Genetic variation analysis for 27 SSRs markers studied among Z. nummularia genotypes 


\begin{tabular}{|c|c|c|c|c|c|c|c|c|c|c|c|c|c|c|c|}
\hline Locus & $\begin{array}{l}\text { Sample } \\
\text { Size }\end{array}$ & BP & $\begin{array}{l}\text { Observed } \\
\text { _Het* }\end{array}$ & $\begin{array}{l}\text { Expected } \\
\text { _Het* }\end{array}$ & Nei** & PIC & GD & $\mathrm{AF}$ & $n e^{*}$ & |* & na* & Fis & Fit & Fst & $\mathrm{Nm} *$ \\
\hline $\begin{array}{l}\text { JSSR- } \\
21\end{array}$ & 184 & 3 & 0.88 & 0.6 & 0.6 & 0.59 & 0.47 & 0.85 & 2.51 & 0.99 & 3 & -0.6 & -0.5 & 0.03 & 7.2 \\
\hline $\begin{array}{l}\text { JSSR- } \\
93\end{array}$ & 268 & 3 & 0.78 & 0.6 & 0.6 & 0.55 & 0.42 & 0.76 & 2.51 & 0.99 & 3 & -0.3 & -0.29 & 0.01 & 33.77 \\
\hline $\begin{array}{l}\text { JSSR- } \\
95\end{array}$ & 266 & 5 & 0.95 & 0.76 & 0.76 & 0.75 & 0.61 & 1.1 & 4.13 & 1.49 & 5 & -0.3 & -0.26 & 0.05 & 4.75 \\
\hline $\begin{array}{l}\text { JSSR- } \\
97\end{array}$ & 222 & 6 & 0.48 & 0.73 & 0.72 & 0.79 & 0.53 & 0.96 & 3.62 & 1.46 & 6 & 0.17 & 0.33 & 0.19 & 1.06 \\
\hline $\begin{array}{l}\text { JSSR- } \\
110\end{array}$ & 226 & 4 & 0.94 & 0.57 & 0.57 & 0.65 & 0.51 & 0.91 & 2.31 & 0.95 & 4 & -0.7 & -0.65 & 0 & 193.4 \\
\hline $\begin{array}{l}\text { JSSR- } \\
129\end{array}$ & 158 & 4 & 0.22 & 0.39 & 0.39 & 0.61 & 0.36 & 0.65 & 1.64 & 0.77 & 4 & 0.41 & 0.46 & 0.09 & 2.56 \\
\hline $\begin{array}{l}\text { JSSR- } \\
152\end{array}$ & 250 & 6 & 0.97 & 0.71 & 0.7 & 0.77 & 0.29 & 0.53 & 3.38 & 1.43 & 6 & -0.4 & -0.38 & 0 & 67.41 \\
\hline $\begin{array}{l}\text { JSSR- } \\
175\end{array}$ & 250 & 5 & 0.11 & 0.54 & 0.54 & 0.72 & 0.55 & 0.99 & 2.16 & 0.92 & 5 & 0.82 & 0.82 & 0.01 & 33.35 \\
\hline $\begin{array}{l}\text { JSSR- } \\
181\end{array}$ & 198 & 5 & 0.91 & 0.68 & 0.68 & 0.70 & 0.66 & 1.19 & 3.13 & 1.28 & 5 & -0.4 & -0.35 & 0.02 & 11.82 \\
\hline $\begin{array}{l}\text { JSSR- } \\
183\end{array}$ & 186 & 4 & 0.87 & 0.57 & 0.56 & 0.67 & 0.66 & 1.19 & 2.29 & 0.94 & 4 & -0.6 & -0.6 & 0.01 & 48.42 \\
\hline $\begin{array}{l}\text { JSSR- } \\
188\end{array}$ & 298 & 6 & 0.97 & 0.72 & 0.72 & 0.77 & 0.44 & 0.8 & 3.53 & 1.44 & 6 & -0.4 & -0.35 & 0 & 74.54 \\
\hline $\begin{array}{l}\text { JSSR- } \\
192\end{array}$ & 238 & 6 & 0.94 & 0.73 & 0.73 & 0.73 & 0.32 & 0.57 & 3.65 & 1.48 & 6 & -0.3 & -0.31 & 0.01 & 38.24 \\
\hline $\begin{array}{l}\text { JSSR- } \\
207\end{array}$ & 300 & 4 & 0.95 & 0.62 & 0.62 & 0.54 & 0.72 & 1.3 & 2.64 & 1.05 & 4 & -0.6 & -0.53 & 0.01 & 21.39 \\
\hline $\begin{array}{l}\text { JSSR- } \\
209\end{array}$ & 190 & 5 & 0.16 & 0.48 & 0.47 & 0.68 & 0.49 & 0.88 & 1.9 & 0.78 & 5 & 0.68 & 0.69 & 0.05 & 4.49 \\
\hline $\begin{array}{l}\text { JSSR- } \\
239\end{array}$ & 236 & 3 & 0.62 & 0.51 & 0.51 & 0.59 & 0.41 & 0.73 & 2.03 & 0.74 & 3 & -0.2 & -0.22 & 0.02 & 14.84 \\
\hline $\begin{array}{l}\text { JSSR- } \\
222\end{array}$ & 262 & 5 & 0.33 & 0.59 & 0.59 & 0.72 & 0.58 & 1.04 & 2.44 & 1.18 & 5 & 0.16 & 0.38 & 0.26 & 0.71 \\
\hline $\begin{array}{l}\text { JSSR- } \\
247\end{array}$ & 128 & 3 & 0.44 & 0.53 & 0.52 & 0.59 & 0.65 & 1.17 & 2.1 & 0.9 & 3 & 0.12 & 0.14 & 0.02 & 13.07 \\
\hline $\begin{array}{l}\text { JSSR- } \\
261\end{array}$ & 290 & 3 & 0.34 & 0.31 & 0.3 & 0.47 & 0.51 & 0.92 & 1.44 & 0.58 & 3 & -0.1 & -0.13 & 0.01 & 30.84 \\
\hline $\begin{array}{l}\text { JSSR- } \\
262\end{array}$ & 278 & 3 & 0.86 & 0.61 & 0.61 & 0.56 & 0.41 & 0.74 & 2.55 & 1 & 3 & -0.4 & -0.4 & 0.01 & 16.51 \\
\hline $\begin{array}{l}\text { JSSR- } \\
414\end{array}$ & 200 & 3 & 0.07 & 0.14 & 0.14 & 0.47 & 0.51 & 0.91 & 1.16 & 0.3 & 3 & 0.47 & 0.5 & 0.05 & 4.51 \\
\hline $\begin{array}{l}\text { JSSR- } \\
416\end{array}$ & 138 & 3 & 0.68 & 0.67 & 0.66 & 0.55 & 0.58 & 1.05 & 2.97 & 1.09 & 3 & -0.1 & -0.04 & 0.06 & 3.68 \\
\hline $\begin{array}{l}\text { JSSR- } \\
460\end{array}$ & 210 & 4 & 0.92 & 0.69 & 0.69 & 0.65 & 0.34 & 0.61 & 3.22 & 1.26 & 4 & -0.4 & -0.34 & 0.01 & 37.52 \\
\hline $\begin{array}{l}\text { JSSR- } \\
465\end{array}$ & 248 & 4 & 0.96 & 0.63 & 0.62 & 0.65 & 0.48 & 0.87 & 2.66 & 1.07 & 4 & -0.5 & -0.54 & 0 & 92.14 \\
\hline $\begin{array}{l}\text { JSSR- } \\
485\end{array}$ & 176 & 3 & 0.57 & 0.49 & 0.49 & 0.50 & 0.52 & 0.93 & 1.95 & 0.8 & 3 & -0.2 & -0.2 & 0.02 & 16.04 \\
\hline $\begin{array}{l}\text { JSSR- } \\
490\end{array}$ & 224 & 2 & 0.21 & 0.24 & 0.24 & 0.33 & 0.29 & 0.52 & 1.31 & 0.4 & 2 & 0.09 & 0.13 & 0.05 & 4.48 \\
\hline $\begin{array}{l}\text { JSSR- } \\
513\end{array}$ & 192 & 4 & 0.88 & 0.73 & 0.73 & 0.65 & 0.28 & 0.51 & 3.68 & 1.34 & 4 & -0.2 & -0.2 & 0.03 & 9.48 \\
\hline $\begin{array}{l}\text { JSSR- } \\
774\end{array}$ & 300 & 5 & 0.89 & 0.68 & 0.68 & 0.75 & 0.55 & 0.99 & 3.14 & 1.3 & 5 & -0.3 & -0.3 & 0 & 57.96 \\
\hline Mean & 227 & 4.43 & 0.662 & 0.575 & 0.572 & 0.671 & 0.494 & 0.89 & 2.6 & 1.03 & 4.11 & -0.2 & -0.17 & 0.04 & 6.415 \\
\hline
\end{tabular}


Note; * Expected homozygosity and heterozygosity were computed using, ${ }^{*}$ Nei's (1973) expected heterozygosity ${ }^{*} P=$ Polymorphic bands * ne $=$ Effective number of alleles, $* I=$ Shannon's Information index, ${ }^{*} \mathrm{Nm}=$ Gene flow estimated from Fst $=0.25(1-$ Fst $) /$ Fst.

The population structure analysis was carried out for the 180 Z. nummularia genotypes collected from three geographical regions of KP, Pakistan, were estimated by the user of Bayesian clustering system probabilistically assigned individuals to respective populations there have three types of clustering were identifies which showed relationship among them of different geographical origin, $K$ values were estimated as the mean of the final estimations of $L "$ (K) found the middle value of more than 20 runs isolated by the standard deviation of $L(K), \Delta K=m(\mid L "(K) I) / s[L(K)]$ (Pritchard et al. 2000). For the given ranges, i.e., 1 to 20 and the highest values were recorded in $K=3$ and $K=5$ consequently, the analysis of the STRUCTURE software was performed for the $\mathrm{K}=3$ which largely grouped by the genotypes, according to Pritchard et al. (2010) and Bayes' rule estimation of K, values give a comparative estimation of $\mathrm{LnP}(\mathrm{D})$ and the smallest value is regarded as almost correct. The estimation of $\Delta \mathrm{K}$, values that the peak reached $\mathrm{K}=5$, according to the formula our result shows clear peaks of $\Delta \mathrm{K}$ at $\mathrm{K}=3$ of $Z$. nummularia genotypes accordingly (Fig 5). In the absence of clear-cut origins of the accessions, a non-stratified strategy was adopted for the genetic structure analysis. Our results showed a clear peak for $\Delta K$ at $K=3$, where all the accessions were roughly divided into three major groups, with some admixture among groups (Fig 6). $\Delta \mathrm{K}$ value was recorded in $\mathrm{K}=3$ which were suggested that the $180 \mathrm{Z}$. nummularia genotypes were approximately divided into three Pops (Pop =1, Pop =2 and POP=3) accordingly, (Fig 1 and 2). The genetic relationship among the Pop s provided various confirmations for gene flow between Pop s. Pop $=2$ consisted of the highest number of genotypes 63 , followed by Pop $=3$ having 44 number of genotypes was recorded and while Pop $=1$ as contains 27 genotypes of $Z$. nummularia. Pop $=3$ was comprised almost all of the 'ZNBU was included in Pop $=2$ while of the collected genotypes from ZNDR of the Z. nummularia were assigned to Pop=2 and Pop =3. Notably, which were highly adaptable to moderate climates, were included in $\mathrm{Pop}=2$ and $\mathrm{Pop}=3$, 'suggesting that it may have a unique ancestry type. Statistical analysis indicated that the percentage of genotypes with a membership coefficient $\geq$ of $67 \%$ was $45.00 \%$. A total of $60.00 \%$ of genotypes exhibited a membership coefficient $\geq$ of $73 \%$, and only $1.99 \%$ of the genotypes exhibited a membership coefficient of $3.2 \%$ or less. Based on standard permutation tests of the full data set, the groups defined by Structure suggest moderate genetic differentiation, as indicated by the global Fst mean value of 0.038 ( $P<0.01)$. Pairwise FST comparisons among the different geographical regions showed that FST values varied from 0.0013 to 0.1913 respectively, (Table 5).

\section{Neighbor-joining (NJ) and Principal coordinate analysis (PCoA)}

The neighbor-joining system was used for the composite phylogenetic tree for the $180 \mathrm{Z}$. nummularia genotypes collected from three geographical regions. Viz, ZNST, ZNDR and ZNBU (Swat, Dir, and Buner) of KP, Pakistan, largely agreed with the results of the STRUCTURE analysis showed that, in general, the genotypes from the different regions were clustered together represented three clusters i.e. Cluster 1, cluster 2 and cluster 3, (Fig 7). Cluster 1 was the largest group which comprised mainly the ZNBU, 16 genotypes from ZNST regions and 27 genotypes from ZND region, Cluster, 2 contained a total of 40 genotypes, 9 from ZNBU, 03 were ZNDR and 28 from ZNST regions, Cluster, 3 comprised most genotypes ZNST (Swat), from ZNBU (Buner). The 54 Z. nummularia genotypes were separated into two sub-clusters within the cluster (Fig 3), sub-cluster 2 comprised only ZNST, Z. nummularia genotypes subcluster 1 included ZNBU and ZNDR respectively, however, and there is very strong support for clustering genotypes with related geographical origins.

The PCoA (Principal co-ordinate analysis) were divided into three clusters (Fig 8), which contained the assignments composite by ZN clustering method and population structure (Fig 5 and 7) respectively. The majority of Z. nummularia genotypes belonging to cluster I, ZNST genotypes were distributed in the left half of the PCoA plot. While the rest of the Z. nummularia genotypes from district ZNBU and ZNDR regions belonging to clusters II and III are distributed in the right of the PCoA plot. The distribution of cluster I was more widely scattered than clusters II and III, indicating that $Z$. nummularia genotypes of the Swat region had higher diversity than the genotypes of Buner and Dir regions. The PCoA results corresponded to cluster analysis as the Swat genotypes were close to Dir and Buner genotypes were joined with Buner region of $Z$. nummularia genotypes.

\section{Analysis of molecular variance (MOVA)}

The genetic diversity was recorded within and among the population of different geographical regions and population structure providing arranged data for the hierarchical AMOVA (analysis of molecular variance), the current total genetic variances among the population $8 \%$ while differences among individuals within populations contributed $12 \%$ to total variance and $72.00 \%$ of the total variance occurred within individuals. The determination of FIS value as 0.102 , FIT showed the highest level of genetic variation as 0.105 and FST values 0.092 respectively, suggesting that the fixation index value of the $Z$. nummularia genotypes was highly significant (P-Value 0.001), (Table 5).

Table 5. AMOVA (Analysis of molecular variance) for the 180 Z. nummularia genotypes

\begin{tabular}{|c|c|c|c|c|c|c|}
\hline Source & Df & SS & Component of variance & Percentage of variation & Fixation index & P-Value \\
\hline Among Populations & 2 & 82.985 & 0.321 & $8 \%$ & Fst 0.092 & 0.001 \\
\hline Among Individual with in Population & 176 & 565.959 & 0.453 & $12 \%$ & Fis 0.102 & 0.001 \\
\hline Within Individual & 179 & 559.000 & 3.123 & $80 \%$ & Fit 0.105 & 0.001 \\
\hline Total & 357 & 1207.944 & 3.490 & $100 \%$ & & \\
\hline
\end{tabular}

Note: df, degrees of freedom; SSD, sum of squares; FIT, fixation index within individuals; FIS, Fixation index among populations; FST, among individuals within populations.

\section{Discussion}


Z. nummularia and forecast an especially uncertain future for this rare species of Ziziphus species, which is native of Malakand division, KP, Pakistan. It is looking likely that $Z$. nummularia is going to harshly reduce ranges, as recommended by the up to $99 \%$ decreases of the suitable habitats across all the global climatic models during these periods and due to the result, the plant species are more likely and highly risk extinction by the local restriction. Climatic changes have already affected by several plants species which were distributed in all over the world and mostly tropical and subtropical region of the world has been identified as the most sensitive regions in the (remote) of Pakistan, which the projection percentages species loss will be reach to $60 \%$ by 2080 (Appleby et al. 2009).

As Hindukush regions range in the northern regions of Pakistan many plant species, one of the $Z$. nummularia, we are likely going to face a wave of mass extinction of $Z$. nummularia genus over the coming periods. However, the high level of genetic diversity of the current $Z$. nummularia genus may eventually favor adaptation and perseverance remains high ambiguous and species growth will depend on factors such as genetic makeup, fitness, healthy habitat, and fragmentation while dispersal approaches, While the seed of Z. nummularia by the lacking of obvious adaptations for the long-distance and brochure, is likely the great dispersal mod, it required the mean way like grazing mammals that consume the seeds along with the foliage cannot be ruled out (Doebley et al. 2008)

\section{Morphological variation in Z. nummularia genotypes}

The total 11 quantitative morphological traits are often known to be influenced by environmental factors, but there has been the most important of these traits cannot be underestimated for analyzing the diversity of a Ziziphus species in mostly for $Z$. nummularia genotypes and crop species as they are the primary constituents of overall diversity. Different types of systems, the method as well researchers have been utilized for morphological variation in combination with molecular markers to precisely estimate characteristic variability for drawing inferences in many crops and trees which as including Ziziphus species (Z. nummularia), (Smykal et al. 2008; Sharma et al. 2010; Pachauri et al. 2013).

In the current study, the information generated through multivariate analysis and genetic parameters has given an excellent view of genetic diversity for the 11 quantitative traits for the 180 Z. nummularia genotypes collected from different regions (Swat, Dir, and Buner) of KP, Pakistan. The level of variation was enough to discriminate against many genotypes for $Z$. nummularia from each other in our study. This agreed with many earlier studies involving morphological traits that distinguished different genotypes among the three regions of KP, Pakistan (Sarıkamış et al. 2010; Gixhari et al. 2014). High LL (Leaf length) suggests for ZNST, ZNDR, and ZNBU, that these traits may be under the influences of additive genes interactions and the use of the simple's selection methods (Single replication, single plant selection) would be sufficient for further improvement of these traits (Kumar 2008; Ahmad et al. 2010). Correlation coefficients are important in plant breeding because they measure the degree of association (genetic and non-genetic) between 2 or more traits in the presence of a high correlation between different traits, selection for a particular trait will cause a change in its mean through additive gene effects of selected individuals and simultaneously cause an indirect change in the mean of the other trait (Singh et al. 2015). The significant positive correlations of FtW with LL, LW and FtL represented that they showed that selection for any of these traits may favor improvement in fruit production.

\section{Genetic differentiation and population structure analysis}

For the genetic diversity using various parameters of the SSR loci, viz, the mean values of allele frequency, allele numbers, observed and expected heterozygosity and PIC as well, are important to reveal the genetic diversity of $Z$. nummularia genotypes these parameters were present to be high in the current study. An average of 4.4286 alleles per locus was higher than in the previous studies conducted on the different plants (Smykal et al. 2008; Ponnaiah et al. 2011; Ahmad et al. 2012; Uddin et al. 2021). Similarly, the average PIC value recorded in our study was almost 0.671 which was greater than the average PIC obtained by Ponnaiah et al. (2011), Ahmad et al. (2012) and Cieslarová et al. (2012). However, in another study carried out by Smykal et al. (2008), higher PIC values were obtained by using SSR markers. Likewise, the mean heterozygosity value was higher than detected in the studies done by other workers (Hagenblad et al. 2014). The average Shannon's Information Index (I) value of 1.0339 was also almost similar was observed by different citation and coworkers Cieslarová et al. (2012) who reported an average I value of 1.22 with SSR markers and an average I value of 0.59 using retrotransposon markers in pea cultivars.

High estimated obtained for all diversity parameters indicated allelic richness in the analyzed genotypes, which can be utilized in breeding programmed to get the desired plant types for breeding. 120 total polymorphic alleles were recoded while the highest alleles 6 per locus while 2 is lowest alleles are noted and average values as 4.4286 respectively, this information can be helpful for future genetic analysis specific to linkage groups. The analysis of molecular variance $(A M O V A)$ results showed major and significant $(80 \% ; P=0.001)$ contribution of within-individual difference to a total variation, whereas amongindividual and among-population differences contributed 12 and $8 \%$, respectively.

For the population, structure performs a Bayesian genetic and admixture by modal STRUCTURE software was assigned all $Z$. nummularia genotypes of all three different geographical origins into three structure genetic clusters. In addition to assigning individuals to different clusters based on allele frequencies, it also detected the extent of admixture within genotypes of the three genetic clusters obtained with STRUCTURE, clusters Pop 2 broadly contained Z. nummularia genotypes collected from Dir region, (ZNDR), respectively, while Pop 1 and Pop 3 were different types which were a mixture of ZNBU and ZNST regions genotypes. This clustering of pea accessions agreed with the study carried out by Jing et al. (2012) who also showed robust clustering at $\mathrm{K}=3$, although the germplasm analyzed by them contained different species and subspecies. The mixing seems dominant over the factors such as the self-pollination behavior of the crop and the wide geographical range/barriers. One of the striking observations of the STRUCTURE analysis was that the genotype of ZNDR represented no admixture with the ancestries, with the genotypes of ZNST and ZNBU begin differently from that of other 
pure ancestries. This indicates that these were probably the regions from which a large amount of dispersal of genotypes has taken place in previous times.

The molecular phylogenetic and PCoA analysis was applied for the identification of Z. nummularia genotypes and they were found in ideal molecular markers for the making of molecular phylogenetic relationships in Z. nummularia genotypes of the different geographical origin of KP, Pakistan. The N-J Phylogenetic tree distributed all Z. nummularia genotypes into three clusters, which was in correspondence with our previous studies and while reported studies (Jing et al. 2012; Kumari et al. 2013), who also reported the same number of groups from different plants genotypes from different geographical regions. Furthermore, assignment of genotypes into groups appeared independent of geographic origins but in cluster 1 and cluster 3 has been most of the genotypes were collected from ZNST and ZNBU regions of KP, while cluster 2 were having the ZNDR region of $Z$. nummularia genotypes from distant geographical locations which obstructed their specificity to geographic origins. Similar results were obtained by Ahmad et al. (2010) in cluster analysis where they found intermixing of $Z$. nummularia genotypes in different groups. When analyzed concerning gene pools detected by STRUCTURE, the groupings of the N-J tree appeared stronger with a few exceptions where cluster I, 17 genotypes from cluster I from Dir region, while 30 genotypes from cluster III from Buner region, while in cluster II having 3 genotypes from (ZNST 1, ZNST 9 and ZNST 43), respectively, and 9 from cluster I (ZNBU 1, ZNBU 29, ZNBU 33, ZNBU 3, ZNBU 9, ZNBU 43, ZNBU 7, ZNBU 19 and ZNBU 32) respectively, cluster III having a mixture of all three regions genotypes 17 genotypes from cluster I and 15 from cluster II ZNDR, From this, it can be inferred that the clustering of $Z$. nummularia genotypes was based on genetic stocks regardless of geographic proximities. This could be conveniently ascribed to the movement of germplasm from one location to another from ancient times, the records for which are missing, and presently formal germplasm exchange agreements are in place between different regions as described by Kuleung et al. (2006) and Ahmad et al. (2010). Thus, the present study further suggests that, despite its self-pollinating nature, there is sample intermixing of $Z$. nummularia genotypes collected from KP, Pakistan, which has resulted in maintaining diversity to a greater extent than can be surveyed and utilized by breeders to develop new improved varieties in the Z. nummularia, the $\mathrm{N}-\mathrm{J}$ result were complemented with PCoA analysis.

\section{The implication for potential breeding and conservation}

The global application of molecular markers (Molecular genetic diversity), technologies are attracting more and more common practices to the estimation and study of many aspects of plant genetic resources management (Inouye, 2008). The current study SSRs markers analysis was used to validate taxonomic origin, to determine the distribution of genetic diversity across the collection area of the wild Ziziphus species.

The field assessment of the collection revealed some interesting traits useful for Ziziphus species genetic improvement (Ferris et al. 2017). Achieving genetic gain through conventional breeding takes a very long time for $Z$. nummularia because approximately four to five years is required to complete one cycle of field data collection and evaluation for the species. Therefore, appropriate planning to preserve individual palms that possess traits of interest should be in place to ensure long-term accessibility. The values of the current potential collection where determined genetic diversity is preserved in a reduced land size can be applied. The establishment of such a collection is an ideal option for oil palm as it increases the efficiency of conservation and allows for more effective access to genetic materials. The results presented above facilitate the identification of unique populations or rich allelic individual palms as well as populations that exhibit high genetic variation (Veltman et al. 2019).

The present findings are strongly suggested that there is wide genetic diversity are present in the wild within genotypes of $Z$. nummularia collected from the area of KP, Pakistan, conservation approach addressed to preserve single outstanding individuals is necessary, namely for the importance of heritage trees which often become one of the few objects of great natural value in areas under the impact of land degradation and the falling into the decay of rural areas (Veltman et al. 2019). Knowledge of genetic variation within and among populations provides information essential in the formulation of appropriate management strategies for conservation (Sharma et al. 2016). The natural areas where the species of interest occur may provide relevant information to develop sampling strategies that will maximize the probability of collecting genetically distinct samples. Based on the results of the present study, the probability of sampling identical or very similar genotypes of $Z$. nummularia increases when sites are sampled less than $20 \mathrm{~km}$ apart even though even very distinct samples, albeit in a low frequency, can be obtained from the same site, a distance of $20 \mathrm{~km}$ between collection sites could be used as a general guideline in future collection missions to maximize the diversity captured for $Z$. nummularia and while in the current result represented that the Pakistani $Z$. nummularia genotypes are exceptionally diversity/variable that this can be endorsed to diver's neighborhood genetic basics, specific reproducing weights and the restricted trade of hereditary material (Uddin et al. 2021). The exceptional nature of the Pakistani Ziziphus species, uncovered by our results, backs the case for the execution of more extraordinary characterization and preservation procedures and potential rearing for Ziziphus species (Z. nummularia).

\section{Conclusion}

The effect and the incensement of global climate changes in recent years, while the reason of the climate changes heavy rainfall has caused floods (disaster) in various areas and weather station over the world measured the increasing concentration of atmospheric $\mathrm{CO}_{2}$ up to $400 \mathrm{pp}$, the highest in millions of years mostly the climate changes exceedingly highly effects on plants and wildlife, respectively. Hear, Z. nummularia from different geographical locations of Pakistan and China were investigated for their genetic variability using 27 SSR markers and reported extensive diversity within the wild collection with significant positive correlation and descriptive analysis showed a high coefficient of variation between the study's morphological traits was noted. We first time establish SSRs fingerprints 180 genotypes and provide a comprehensive data of genetic diversity and their population structure and their relationships addressed with their geographical/climatic distribution was addressed. Better understanding of plants genetic diversity is essential to all conservation and management effort. Remarkably, wise utilization of conserved plant germplasm in a gene bank collection needs knowledge of the genetic diversity that is present as well. Ensuring sustainable food security is a multi-faceted challenge, involving much more than just increasing food production; it is also about protecting the useful diversity of wild. The results shown here may provide valuable resources for future

Page $11 / 16$ 
Ziziphus breeding programs. Further, the application of the recently evolved high-throughput platforms and phenomics tools could enable plant breeders to identify and exploit the available plant genetic resources in environmentally sustainable ways. In brief, the current result will be highly beneficial in designing studies relating to Ziziphus species (Z. nummularia) genotypes phylogeny as well as to find the biological origin and formulating future breeding programs.

\section{Declarations}

Authors Contribution: All authors have contributed as follows: NU performed the molecular biology experiments; NU, MN and NA wrote the paper, NM, MUK and MR helped in reviewing. All authors read, contributed to, and approved the final manuscript.

Acknowledgments We thank the "the significance Found of Hebei Province Natural Sciences Foundation" with the grant number as (C2017204114) and Research Center of Chinese Jujube, Hebei Agricultural University Baoding, Hebei, China, for granting research scholarships and for funding this project.

Declaration and Conflicts of Interest: The authors declare that there is no conflict of interest.

\section{References}

1. Ahmad G, Kudesia R, Srivastava MK (2010) Evaluation of genetic diversity in pea (Pisum sativum L) using RAPD analysis. Genetic Engineering Biotechnology Journal 16:1-5

2. Appleby N, Edwards D, Batley J (2009) New technologies for ultra-high throughput genotyping in plants In Plant genomics (pp. 19-39)

3. Arndt SK, Clifford SC, Wanek W, Jones HG, Popp M (2001) Physiological and morphological adaptations of the fruit tree Ziziphus rotundifolia in response to progressive drought stress. Tree physiology 21(11)):705-715

4. Botstein D, White RL, Skolnick M, Davis RW (1980) Construction of a genetic linkage map in man using restriction fragment length polymorphisms. Am J Hum Genet 32(3):314

5. Chen XJ, Min DH, Yasir TA, Hu YG (2012) Genetic diversity., population structure and linkage disequilibrium in elite Chinese winter wheat investigated with SSR markers. PLoS One 7:e44510

6. Cieslarová J, Hýbl M, Griga M, Smýkal P (2012) Molecular analysis of temporal genetic structuring in pea (Pisum sativum L.) cultivars bred in the Czech Republic and in former Czechoslovakia since the mid-20th century. Czech Journal of Genetics Plant Breeding 48(2):61-73

7. Evanno G, Regnaut S, Goudet J (2005) Detecting the number of clusters of individuals using the software STRUCTURE: a simulation study. Molecular ecology 14(8):2611-2620

8. Ferguson ME, Burow MD, Schulze SR, Bramel P, Paterson AH, Kresovich S, Mitchell S (2004) Microsatellite identification and characterization in peanut (A. hypogaea L.). Theor Appl Genet 108(6):1064-1070

9. Ferris KG, Barnett LL, Blackman BK, Willis JH (2017) The genetic archi-tecture of local adaptation and reproductive isolation in sympatry within the Mimulus guttatus species complex. Mol Ecol 26(1):208-224

10. Gimenes MA, Hoshino AA, Barbosa AV, Palmieri DA, Lopes CR (2007) Characterization and transferability of microsatellite markers of the cultivated peanut (Arachis hypogaea L.). BMC Plant Biol 7:9

11. Gixhari B, Pavelkova M, Ismaili H, Vrapi H, Jaupi A, Smýkal P (2014) Genetic diversity of Albanian pea (Pisum sativum L.) landraces assessed by morphological traits and molecular markers. Czech Journal of Genetics Plant Breeding 50(2):177-184

12. Hagenblad J, Zie J, Leino MW (2012) Exploring the population genetics of genebank and historical landrace varieties. Genet Resour Crop Evol 59(6):1185-1199

13. Hammer K, Heller J, Engels J (2001) Monographs on underutilized and neglected crops. Genetic Resources Crop Evolution 48(1):3-5

14. Herselman $L$ (2003) Genetic variation among southern African cultivated peanut (Arachis hypogaea L.) genotypes as revealed by AFLP analysis Euphytica. 133: 319-327

15. Huang L, Jiang HF, Ren XP, Chen YN, Xiao YJ (2012) Abundant microsatellite diversity and oil content in wild Arachis species. PLoS One., e50002

16. Inouye (2008) Effects of climate change on phenology., frost damage., and floral abundance of montane wildflowers. Ecology 89:353-362

17. Jing R, Ambrose MA, Knox MR, Smykal P, Hybl M, Ramos A, Ellis TN (2012) Genetic diversity in European Pisum germplasm collections. Theoretical applied genetics 125(2):367-380

18. Kuleung C, Baenziger PS, Kachman SD, Dweikat I (2006) Evaluating the genetic diversity of triticale with wheat and rye SSR markers. Crop Sci 46(4):1692-1700

19. Kumar K (2008) Variability heritability and genetic advance in pean (Pisum sativum L.). Intonational Journal of Plant Science 3(1):211-212

20. Kumari P, Basal N, Singh AK, Rai VP, Srivastava CP, Singh PK (2013) Genetic diversity studies in pea (Pisum sativum L.) using simple sequence repeat markers. Genet Mol Res 12(3):3540-3550

21. Liang J, Lu Y, Xiao P, Sun M, Corke H (2010) Genetic diversity and population structure of a diverse set of rice germplasm for association mapping. Theor Appl Genet 121:475-487

22. Liu J, Liu H, Ma L, Wang S, Gao J, Li Y, Wu R, Pang X (2014) A Chinese jujube (Ziziphus jujuba Mill.) fruit-expressed sequence tag (EST) library: Annotation and EST-SSR characterization. Sci Hortic 165:99-105

Page $12 / 16$ 
23. Nisar U, Noor M, Nisar M, Muhammad J, Ali N (2019) Genetic diversity in the natural population of Ziziphus jujuba Miil. 4. 29-35

24. Pachauri V, Taneja N, Vikram P, Singh NK, Singh S (2013) Molecular and morphological characterization of Indian farmers rice varieties (Oryza sativa L.). Australian Journal of Crop Science, 7(7), p.923

25. Peakall R (2012) GENALEX, 6: genetic analysis in Excel. Population genetic software for teaching and research. Bioinformatics, 28, p.19

26. Ponnaiah M, Shiferaw E, Porceddu E (2011) Development and application of EST-SSRs for diversity analysis in Ethiopian grass pea. Plant Genetic Resources, 9(2), p.276

27. Pritchard JK, Stephens M, Donnelly P (2000) Inference of population structure using multilocus genotype data. Genetics 155(2):945-959

28. Rana JC, Chahota RK, Sharma V, Rana M, Verma N, Verma B, Sharma TR (2015) Genetic diversity and structure of Pyrus accessions of Indian Himalayan region based on morphological and SSR markers. Tree Genet Genomes 11(1):821

29. Sarıkamış G, Yanmaz R, Ermiş S, Bakır M, Yüksel C (2010) Genetic characterization of pea (Pisum sativum) germplasm from Turkey using morphological and SSR markers. Genet Mol Res 9:591-600

30. Sharma L, Prasanna BM, Ramesh B (2010) Analysis of phenotypic and microsatellite-based diversity of maize landraces in India, especially from the North East Himalayan region. Genetica 138(6):619-631

31. Singh AP, Srivastava RK, Kant R (2015) Assessment of Genetic Variability, Heritability and Character Association in Gamma Rays Induced M. Food Legumes 28(2):113-118

32. Smýkal P, Horáček J, Dostálová R, Hýbl M (2008) Variety discrimination in pea (Pisum sativum L.) by molecular, biochemical and morphological markers. J Appl Genet 49(2):155-166

33. Tang M, Chen YN, Ren XP, Huang L, Zhou XJ (2012) Genetic diversity of Arachis accessions detected by EST-SSR from cultivated peanut (Arachis hypogaea L.). Acta Agron Sin 38:122121231

34. Uddin N, Ali N, Nisar M, Liu M, Liu Z, Muhammad N, Rahman IU (2021) SSR-based population structure, molecular diversity and identity cards of Ziziphus species from Pakistan and China. Genetic Resources and Crop Evolution, 1-19

35. Veltman MA, Flowers JM, van Andel TR, Schranz ME (2019) Origins and geographic diversification of African rice (Oryza glaberrima). PLoS ONE 14(3):e0203508. https:// doi.org/10.1371/journal.pone.0203508

Figures

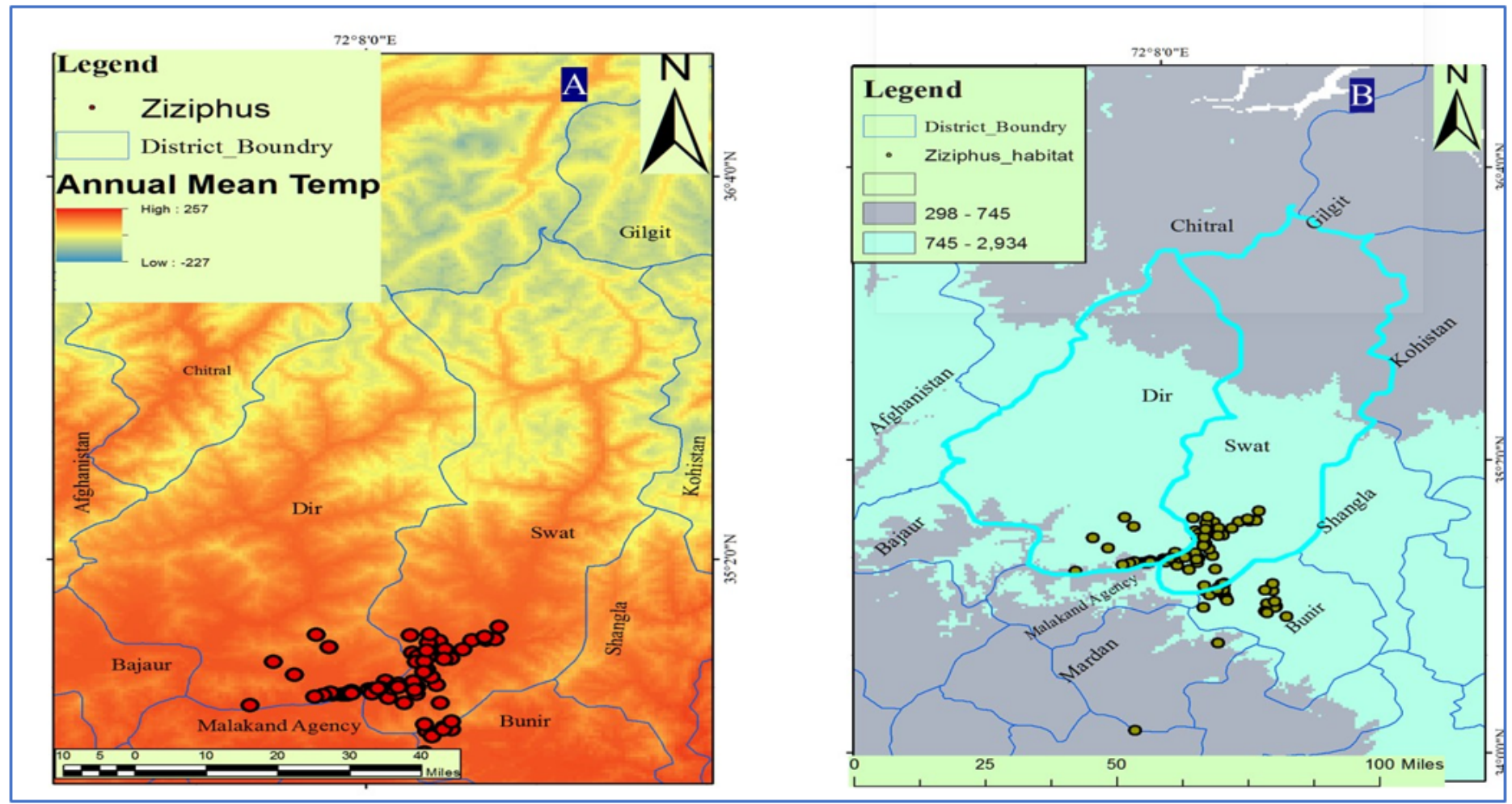

Figure 1

Showed that the ArcGIS mapping of a bioclimatic variable on the selected regions, showing variation in (A), annual mean temperature and (B), annual precipitating. Note: The designations employed and the presentation of the material on this map do not imply the expression of any opinion whatsoever on the part of Research Square concerning the legal status of any country, territory, city or area or of its authorities, or concerning the delimitation of its frontiers or boundaries. This map has been provided by the authors. 


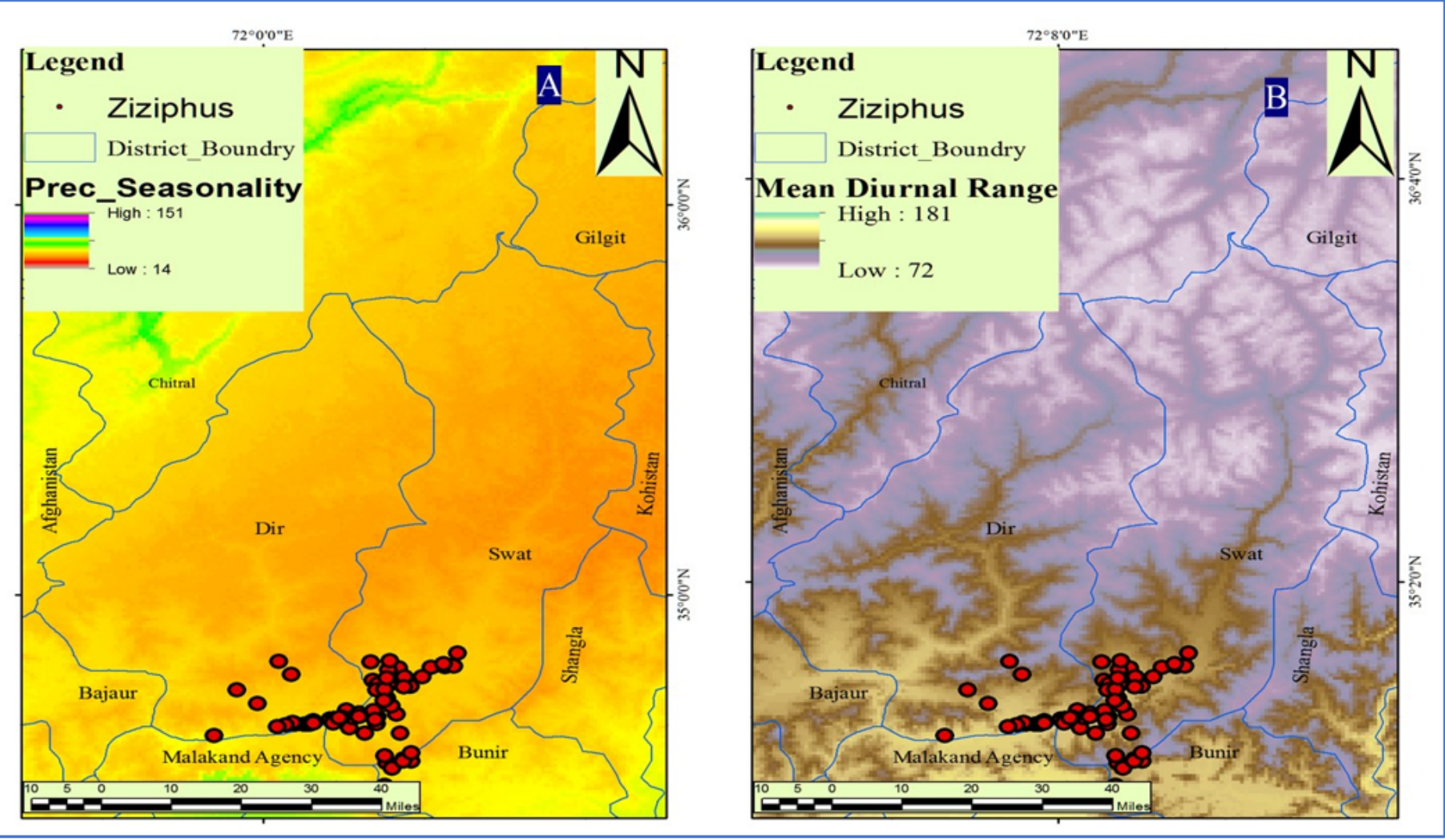

Figure 2

Showed that the ArcGIS mapping of a bioclimatic variable on the selected regions, showing variation in (A), Prec-Seasonality and (B), Mean diurnal range, respectively. Note: The designations employed and the presentation of the material on this map do not imply the expression of any opinion whatsoever on the part of Research Square concerning the legal status of any country, territory, city or area or of its authorities, or concerning the delimitation of its frontiers or boundaries. This map has been provided by the authors.

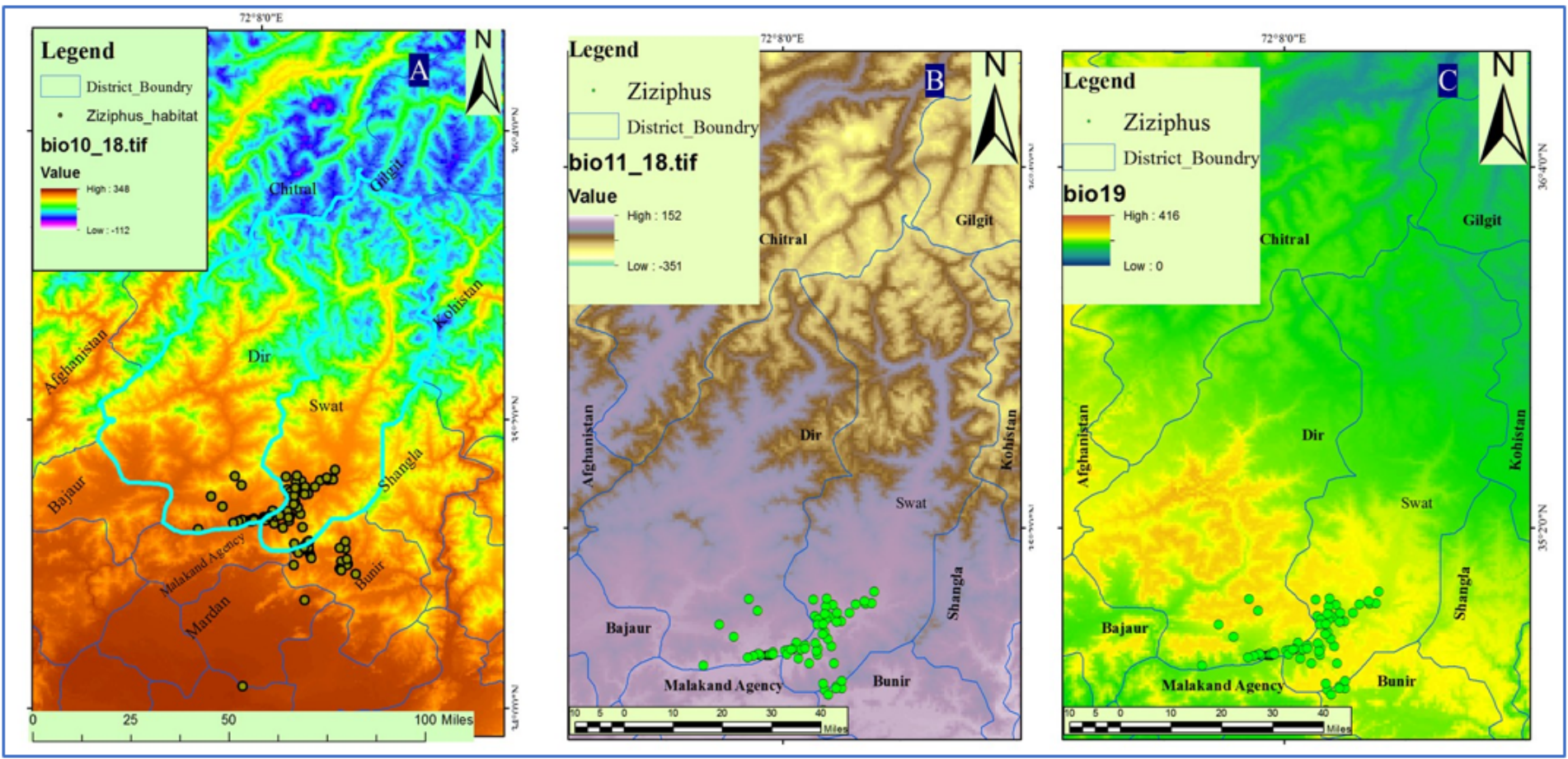

Figure 3

Applied ArcGIS mapping of a bioclimatic variable on the selected regions, (A), distribution in the selected remote regions of Z. nummularia genotypes and ( $B$ and $C$ ), showing accrued temperature ranges. Note: The designations employed and the presentation of the material on this map do not imply the 
expression of any opinion whatsoever on the part of Research Square concerning the legal status of any country, territory, city or area or of its authorities, or concerning the delimitation of its frontiers or boundaries. This map has been provided by the authors.
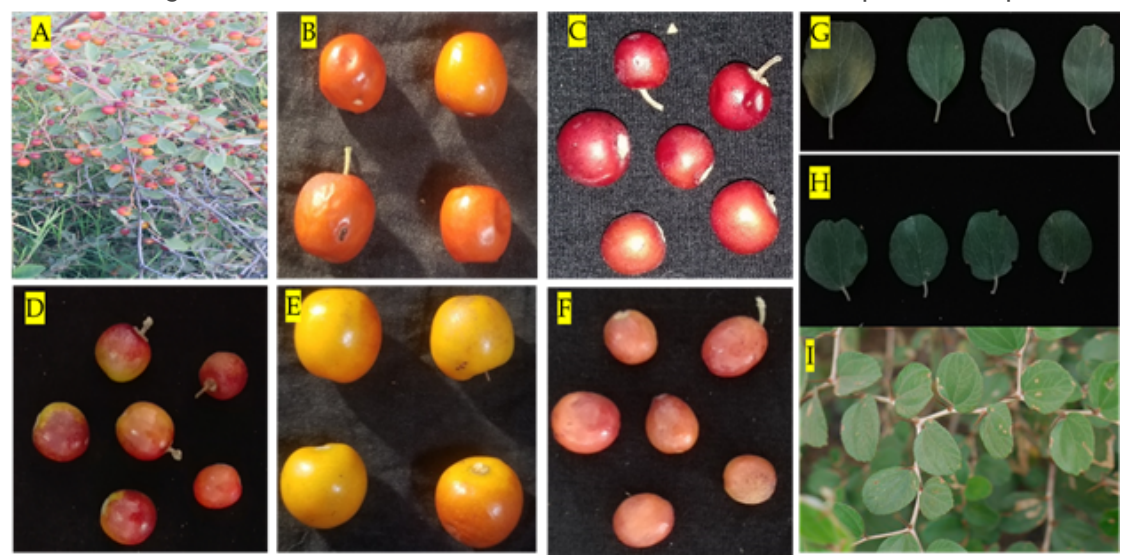

\section{Figure 4}

Photographs collected Z. nummularia fruits and leaves from Malakand Division, KP, Pakistan A to F designated diversity in fruits shape/size and colour and $\mathrm{G}$ to I designated for Z. nummularia leaves diversity

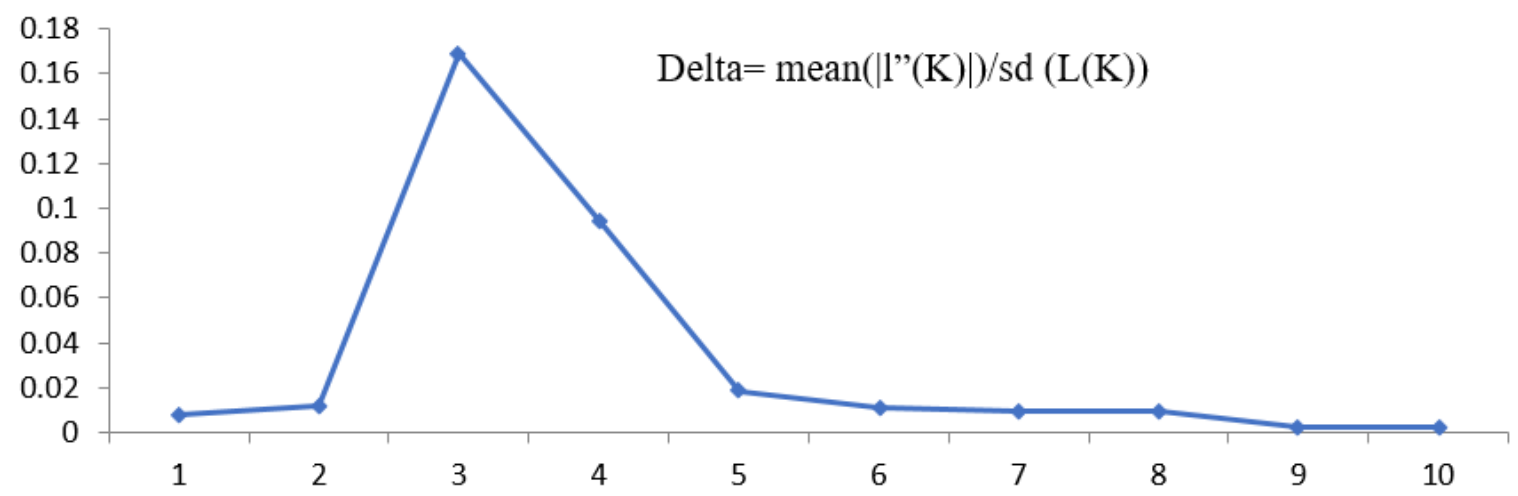

\section{Figure 5}

Showed that the Delta K values for the analysis STRUCTURE of Z. nummularia genotypes, was calculated according to Evanno et al., (2000), is plotted against the number of modeled gene pools $(\mathrm{K})$
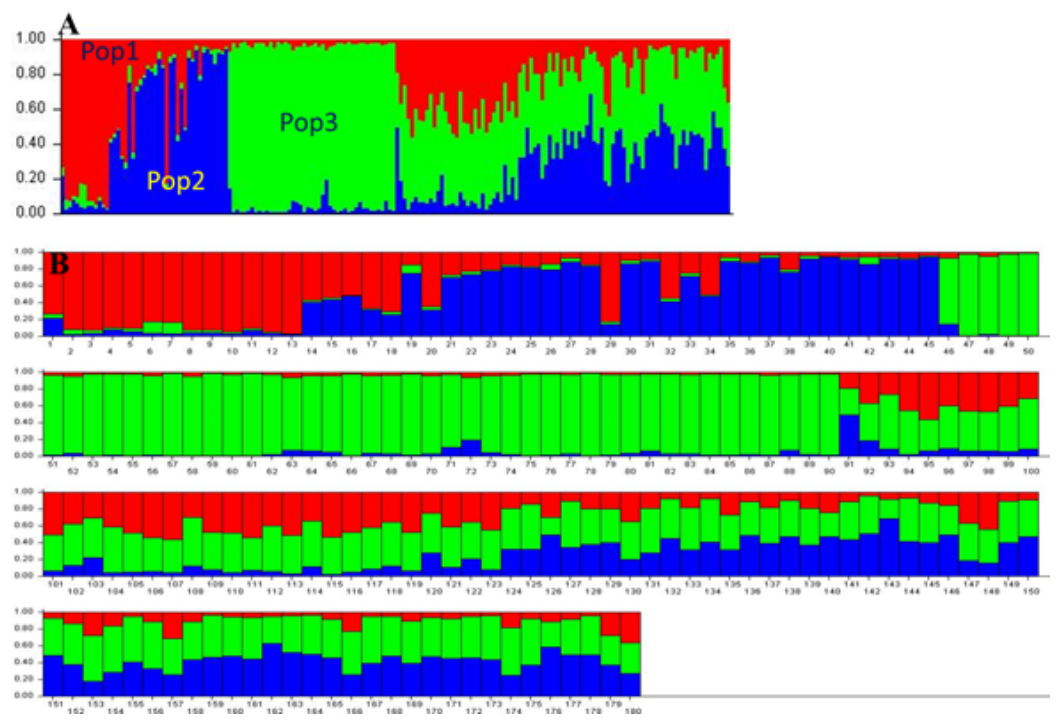

\section{Figure 6}

Population structure analysis presented that the population of $180 \mathrm{Z}$. nummularia genotypes with $\mathrm{K}=3$ clusters based on $27 \mathrm{SSRs}$ primers 


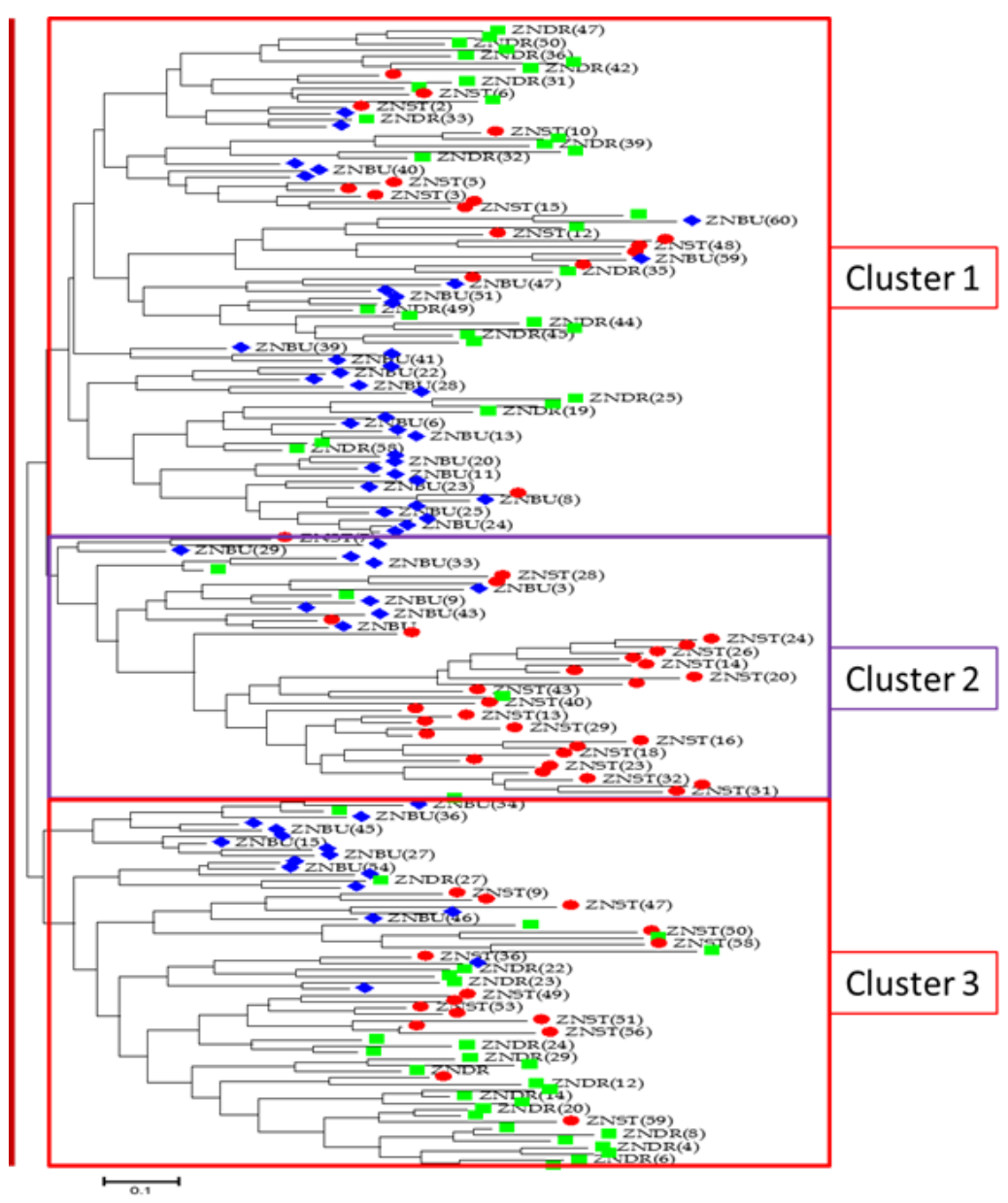

Figure 7

The N-J (Neighbor joining), phylogenetic represented genetic relationship among the Z. nummularia genotypes collected from different geographical regions of KP, Pakistan

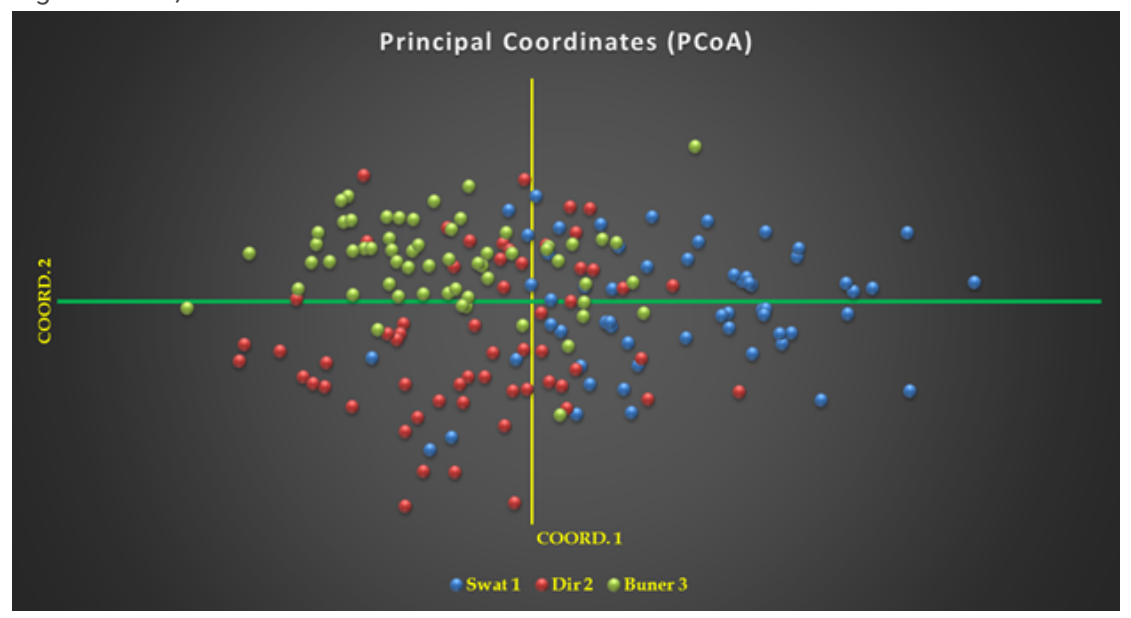

\section{Figure 8}

Principle coordinate analysis (PCoA) plots showing the clusters of among $180 \mathrm{Z}$. nummularia genotypes 